\title{
Evaluation of Power Regeneration in Primary Suspension for a Railway Vehicle
}

\author{
Ruichen WANG ${ }^{1}$, Zhiwei WANG ${ }^{2}(\bowtie)$
}

\begin{abstract}
1 Institute of Railway Research, University of Huddersfield, Huddersfield HD1 3DH, UK 2 State Key Laboratory of Traction Power, Southwest Jiaotong University, Chengdu 610031, China
\end{abstract}

\begin{abstract}
In order to improve the rail vehicle fuel economy, this paper presents the feasibility of power regenerating dampers (PRDs) in railway vehicle primary suspension systems, and the evaluation of the potential and recoverable power that can be obtained. The power regenerating damper is configured as a hydraulic-electromagnetic based railway primary vertical damper and is evaluated in both the 'Parallel Mode' and 'Series Mode' (with and without a viscous damper). Hydraulic configuration converts the linear behavior of the track into a unidirectional rotating of the generator, while the electromagnetic configuration provides a controllable damping force to the primary suspension system. Several case studies of generic railway vehicle primary suspension systems configured to include a power regenerating damper in the two different configuration modes are modelled using computer simulation. The simulations are carried out on measured tracks with typical irregularities for a generic UK passenger route. The performance of the modified vehicle is evaluated with respect to key performance indicator, including regenerated power, ride comfort and running safety. The results are concluded that PRDs are capable of replacing conventional primary vertical damper, regenerating the power and providing the desirable dynamic performances simultaneously. A peak power efficiency of $79.87 \%$ is obtained from 'Series Mode' on a top quality German ICE track ('Track270') at a vehicle speed of $160 \mathrm{mph}$ theoretically.
\end{abstract}

Keywords Railway vehicle, primary damper, power regeneration, ride comfort, running safety

\section{Introduction}

The possibility of using recoverable energy in vehicle suspension systems has attracted significant attention in recent years. Various design concepts and arrangements of regenerative suspensions have been proposed and investigated for the recovery of energy from motion and vibration due to road/track disturbances. However, these studies concentrate on the energy conversion from kinetic energy to electricity in road transports [1-5].

Meanwhile, the potential for similar PRD applications in the rail sector remains to be explored. In a typical passenger rail vehicle, much of motive energy is wasted by the

E-mail: tpl_zw@163.com 
resistance from track irregularity, friction of moving parts and thermal losses. The kinetic energy loss of the primary and secondary dampers is one of the notable causes of energy losses in rail vehicle, with a total dissipated power between 3.5 and $3.8 \mathrm{~kW}$ per vehicle $[6,7]$.

With theoretical modelling analysis, Zuo and Zhang [8] estimate potential energy regeneration in different possible applications such as passenger car, truck, military vehicle and rail car, and showed that $5 \mathrm{~kW}-6 \mathrm{~kW}$ can be recovered from dampers on railway vehicles running on general American track [9]. Although much of the research into regenerative techniques has been done in road vehicles regarding the potential power and regenerated power, the focus of this work aims toward recovering a considerable power from a vertical primary damper in rail vehicle.

Regenerative techniques in vehicle suspension systems can be classified into three main categories according to their operating principles: Mechanical, electromagnetic and hydraulic regenerative suspensions [10,11]. Mechanical regenerative suspension normally uses hydraulic/pneumatic power to convert the kinetic energy into potentially recoverable mechanical energy with control methods, which can be stored for later use [12-17]. Electromagnetic regenerative suspension converts the relative vibration isolation into the linear or rotary motion using electric generators to produce recoverable electricity [18-28]. Hydraulic regenerative suspension converts the reciprocating linear motion into unidirectional rotary motion through the designed hydraulic circuit, and hence to produce electricity by a generator [29-33].

Table 1 Comparisons between different railway dampers-Parallel configurations

\begin{tabular}{|c|c|c|c|}
\hline $\begin{array}{l}\text { Damper } \\
\qquad \text { Power }\end{array}$ & $\begin{array}{c}\text { Potential } \\
\text { Power }\end{array}$ & $\begin{array}{c}\text { Regenerated } \\
\text { Power }\end{array}$ & $\begin{array}{c}\text { Regenerated } \\
\text { Power Efficiency }\end{array}$ \\
\hline Primary & Low & Low & $\underline{\text { High }}$ \\
\hline $\begin{array}{l}\text { Vertical } \\
\text { Damper }\end{array}$ & $(39.07 \mathrm{~W})$ & $(1.47 \mathrm{~W})$ & $3.75 \%$ \\
\hline Secondary & $\underline{\text { High }}$ & $\underline{\text { High }}$ & $\underline{\text { Low }}$ \\
\hline $\begin{array}{l}\text { Lateral } \\
\text { Damper }\end{array}$ & $(4790 \mathrm{~W})$ & $(12.47 \mathrm{~W})$ & $0.67 \%$ \\
\hline Secondary & Very Low & Very Low & Moderate \\
\hline $\begin{array}{l}\text { Vertical } \\
\text { Damper }\end{array}$ & $(25.82 \mathrm{~W})$ & $(0.32 \mathrm{~W})$ & $1.25 \%$ \\
\hline Secondary & $\underline{\text { Moderate }}$ & Moderate & Very Low \\
\hline Yaw Damper & $(3700 \mathrm{~W})$ & $(3.03 \mathrm{~W})$ & $0.08 \%$ \\
\hline
\end{tabular}

Motivated by previous research works, the preliminary evaluation was simulated with 4 different rail vehicle dampers (primary vertical damper, secondary lateral damper, secondary vertical damper and secondary yaw damper), which the power regenerating damper (PRD) is equipped in parallel with each type of damper. It aims to estimate the power capability and adaptability to the rail vehicle suspension systems. Therefore, a comparison of power 
capability in different dampers in rail vehicle was constructed in Table 1, together with those of power efficiency.

For the proposed design of the PRD, the power efficiency of the primary vertical damper reaches the highest efficiency of $3.75 \%$ when the rail car is running at a speed of $160 \mathrm{mph}$ on a top quality German ICE track ('Track270') with $10 \Omega$ internal and external electrical loads. Additionally, considering the damping characteristics of railway dampers (see Table 2 and Fig. 5(b)), the PRD can replace the primary vertical damper to achieve a higher regenerative output power. The PRD allow adjustable damping characterises by applying external load resistance to alter the fluid flow of the hydraulic rectifier, which is similar for commercially used semi-active dampers, such as controllable Magneto-rheological (MR) damper and Electro-rheological (ER) damper [34,35].

To advance power regenerating techniques in railway vehicles, a primary suspension system with efficient power regenerating dampers (PRDs) has been designed and applied to a comprehensive rail vehicle model to characterise the rail vehicle's dynamic response. Because the conventional viscous dampers can transmit the vibrations between track and vehicle carbody is considered to ensure the capabilities of ensure ride comfort and running safety [8,36-38]. A higher level of running safety and ride comfort can ensure the constantly increasing requirements of customer experience and safety [36,39,40]. Therefore, these results have been not only used to investigate the capability of the power regeneration and efficiency, and also evaluate the ride comfort and running safety performance by utilising the design of the PRDs.

The proposed PRDs is configured to operate as the 'Parallel Mode' (Case 1) and 'Series Mode' (Case 2) in order to clarify the influence of damping characteristics and power capability under different running speeds, electrical loads and measured tracks. The main objective of this work is to verify the feasibility of the proposed power regenerating damper in a typical railway application which can be applied to design the semi-active regenerative damper and the further optimisation of the proposed PRDs in future.

In this paper, references and past works have been described first. The preliminary evaluation of the power capability for the railway dampers (primary vertical, secondary vertical, secondary lateral and secondary yaw dampers) has also been introduced. A comprehensive passenger vehicle model is presented in Section 2.1, and the irregularity of the measured tracks and power regenerating damper system layout are introduced in Section 2.2 and 2.3. The brief of ride comfort and running safety for rail vehicle are introduced in Section 2.4 and 2.5. Section 3 discusses the impact factors of different operating conditions and components. Conclusion are summarised in Section 4.

\section{System Modelling}

The dynamics of a passenger vehicle is extremely complex with several significant nonlinearities and substantial undefined variables such as the dynamic contact relations in 
the wheel-rail contact area, the suspension systems and the response of the track. In general, most passenger rail vehicles have a similar basic mode as shown in Fig. 1, which shows a simplified side-view of a half car. The car body is supported by two bogies via the secondary suspension. In each bogie, the wheelsets are connected to the bogie by the primary suspension system (often consisting of passive springs and dampers connected in parallel).

\subsection{Rail Vehicle Model}

In the modelling system, a PRD has been installed in parallel with each primary vertical damper (Case 1) or replaced each primary vertical damper (Case 2) in a rail car to capture the power and search for optimal electrical damping (additional damping) in the vertical direction. The key parameters of a typical UK passenger vehicle are shown in Table 2.

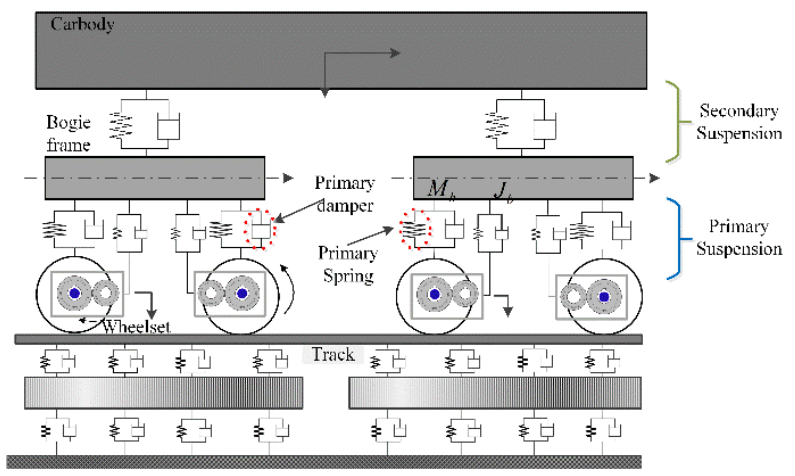

Fig. 1 Simplified side-view of a rail vehicle

Based on the defined typical passenger vehicle model and track data, Fig. 2 illustrates the modelling procedure and performance evaluation including track roughness, dynamic rail vehicle model and rail vehicle response variables in the time domain.

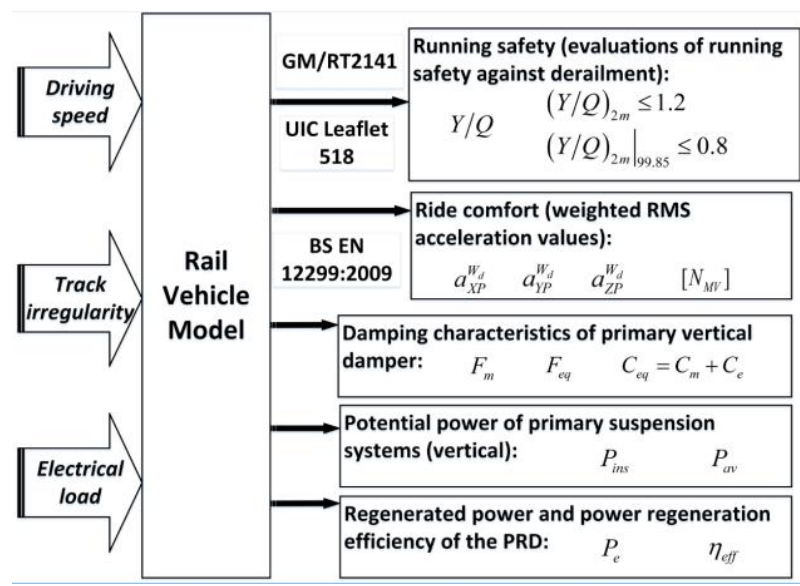

Fig. 2 Block diagram view of overall objective functions in rail vehicle 
The details of the vehicle modelling and objective function calculations are carried out in this domain under various driving speeds and track irregularities and the outputs include primary suspension vertical velocity, wheel-rail contact forces (lateral force and vertical force), weighted RMS accelerations of body centre, pivot 1 and pivot2 (in longitudinal, lateral and vertical directions), damping force, potential power and recoverable power.

Table 2 Values of parameters of a typical passenger rail vehicle [41]

\begin{tabular}{|c|c|c|c|c|c|}
\hline Symbol & Definition & Value & Symbol & Definition & Value \\
\hline$m_{v e h}$ & $\begin{array}{c}\text { Total vehicle } \\
\text { mass }\end{array}$ & $33,000 \mathrm{~kg}$ & $B_{w b}$ & Bogie wheelbase & $2.6 \mathrm{~m}$ \\
\hline$m_{b d}$ & Car body mass & $25,080 \mathrm{~kg}$ & $C_{h}$ & Body height & $1.57 \mathrm{~m}$ \\
\hline$m_{b g}$ & $\begin{array}{l}\text { Total bogie } \\
\text { frame mass }\end{array}$ & $4,180 \mathrm{~kg}$ & $B_{h}$ & Bogie height & $0.5 \mathrm{~m}$ \\
\hline$m_{w s}$ & $\begin{array}{c}\text { Per wheelset } \\
\text { mass }\end{array}$ & $1,120 \mathrm{~kg}$ & $W_{r}$ & Wheel radius & $0.45 \mathrm{~m}$ \\
\hline$k_{s l}$ & $\begin{array}{c}\text { Secondary } \\
\text { lateral stiffness } \\
\text { (Per axlebox) } \\
\end{array}$ & $1.672 \times 10^{6} \mathrm{~N} / \mathrm{m}$ & $H_{s l b d h}$ & $\begin{array}{c}\text { Secondary lateral } \\
\text { damper body end } \\
\text { height }\end{array}$ & $0.53 \mathrm{~m}$ \\
\hline$c_{s l}$ & $\begin{array}{c}\text { Secondary } \\
\text { lateral damping } \\
(\text { per damper } \times 2) \\
\end{array}$ & $25,075.98 \mathrm{Ns} / \mathrm{m}$ & $H_{s l b g h}$ & $\begin{array}{c}\text { Secondary lateral } \\
\text { damper body end } \\
\text { height }\end{array}$ & $0.56 \mathrm{~m}$ \\
\hline$k_{s v}$ & $\begin{array}{c}\text { Secondary } \\
\text { vertical stiffness } \\
\text { (Per axlebox) }\end{array}$ & $1.3672 \times 10^{5} \mathrm{~N} / \mathrm{m}$ & $H_{s v t}$ & $\begin{array}{c}\text { Secondary vertical } \\
\text { damper body end } \\
\text { height }\end{array}$ & $0.96 \mathrm{~m}$ \\
\hline$c_{s v}$ & $\begin{array}{c}\text { Secondary } \\
\text { vertical } \\
\text { damping (per } \\
\text { damper } \times 4)\end{array}$ & $13,373.86 \mathrm{Ns} / \mathrm{m}$ & $H_{s v b}$ & $\begin{array}{c}\text { Secondary vertical } \\
\text { damper bogie end } \\
\text { height }\end{array}$ & $0.895 \mathrm{~m}$ \\
\hline$k_{s y}$ & $\begin{array}{l}\text { Secondary yaw } \\
\text { stiffness (Per } \\
\text { axlebox) }\end{array}$ & $2.09 \times 10^{5} \mathrm{~N} / \mathrm{m}$ & $H_{s y t}$ & $\begin{array}{c}\text { Secondary yaw } \\
\text { damper body end } \\
\text { height }\end{array}$ & $0.61 \mathrm{~m}$ \\
\hline$c_{s y}$ & $\begin{array}{c}\text { Secondary yaw } \\
\text { damping (Per } \\
\text { damper } \times 4) \\
\end{array}$ & $6.687 \times 10^{6} \mathrm{Ns} / \mathrm{m}$ & $H_{s y b g h}$ & $\begin{array}{c}\text { Secondary yaw } \\
\text { damper bogie end } \\
\text { height }\end{array}$ & $0.53 \mathrm{~m}$ \\
\hline$k_{p v}$ & $\begin{array}{l}\text { Primary vertical } \\
\text { stiffness (Per } \\
\text { axlebox) } \\
\end{array}$ & $7.599 \times 10^{5} \mathrm{~N} / \mathrm{m}$ & $H_{p v t}$ & $\begin{array}{c}\text { Primary vertical } \\
\text { damper height (top) }\end{array}$ & $0.81 \mathrm{~m}$ \\
\hline $\begin{array}{c}c_{p v} \\
\text { (Case 1) }\end{array}$ & $\begin{array}{l}\text { Primary vertical } \\
\text { damping (per } \\
\text { damper } \times 8 \text { ) }\end{array}$ & $4,179.33 \mathrm{Ns} / \mathrm{m}$ & $H_{p v b}$ & $\begin{array}{c}\text { Primary vertical } \\
\text { damper height } \\
\text { (bottom) }\end{array}$ & $0.29 \mathrm{~m}$ \\
\hline $\begin{array}{c}c_{p e d} \\
\text { (Case 1) }\end{array}$ & $\begin{array}{c}\text { Electrical } \\
\text { damping } \\
\text { (PRDs, c ced }) \\
\end{array}$ & $\begin{array}{l}\text { [Fig. 5(a)] } \\
\text { Ns/m }\end{array}$ & $L_{h l}$ & Half body length & $12 \mathrm{~m}$ \\
\hline $\begin{array}{c}c_{p e d} \\
\text { (Case 2) }\end{array}$ & $\begin{array}{c}\text { Electrical } \\
\text { damping } \\
\left(\text { PRDs, } c_{\text {ped }}\right)\end{array}$ & $\begin{array}{l}\text { [Fig. 5(b)] } \\
\text { Ns/m }\end{array}$ & $L_{h w}$ & Half body width & $1.4 \mathrm{~m}$ \\
\hline
\end{tabular}




\subsection{Track Irregularity}

The track surface roughness is the key source of track-induced vibration for a railway vehicle. Predefined track using a sinusoidal irregularity with a given frequency and amplitude and using well-defined track inputs which is regarding to a stochastic modelling of the track geometry are insufficient for investigating the performance of a given suspension system or damper system, so a more realistic measured track is considered as inputs in this study, as shown in Table 3.

Table 3 General track data characteristics and descriptions [42]

\begin{tabular}{cccccl}
\hline Track & $\begin{array}{c}\text { Line } \\
\text { Speed }\end{array}$ & Length & $\begin{array}{c}\text { Std. Dev. } \\
\text { (Lateral) }\end{array}$ & $\begin{array}{c}\text { Std. Dev. } \\
\text { (Vertical) }\end{array}$ & \multicolumn{1}{c}{ Description } \\
\hline $\begin{array}{c}\text { Track } \\
110\end{array}$ & $\begin{array}{c}110 \\
\mathrm{~km} / \mathrm{h}\end{array}$ & $5 \mathrm{~km}$ & $3.04 \mathrm{~mm}$ & $5.12 \mathrm{~mm}$ & $\begin{array}{l}\text { A low speed, 110km/h }(70 \mathrm{mph} \text { piece of } \\
\text { UK track, lower quality cross country } \\
\text { track }\end{array}$ \\
\hline $\begin{array}{c}\text { Track } \\
160\end{array}$ & $\begin{array}{c}160 \\
\mathrm{~km} / \mathrm{h}\end{array}$ & $5 \mathrm{~km}$ & $2.46 \mathrm{~mm}$ & $2.77 \mathrm{~mm}$ & $\begin{array}{l}\text { A mainline UK track, } 160 \mathrm{~km} / \mathrm{h} \\
(100 \mathrm{mph}), \text { typical of better quality cross } \\
\text { country and lower quality intercity } \\
\text { routes. }\end{array}$ \\
\hline $\begin{array}{c}\text { Track } \\
200\end{array}$ & $\begin{array}{c}200 \\
\mathrm{~km} / \mathrm{h}\end{array}$ & $5 \mathrm{~km}$ & $1.42 \mathrm{~mm}$ & $2.39 \mathrm{~mm}$ & $\begin{array}{l}\text { A good quality piece of UK mainline } \\
\text { track, 200km/h(125mph), typical of high } \\
\text { speed intercity track }\end{array}$ \\
\hline $\begin{array}{c}\text { Track } \\
225\end{array}$ & $\begin{array}{c}225 \\
\mathrm{~km} / \mathrm{h}\end{array}$ & $5 \mathrm{~km}$ & $1.36 \mathrm{~mm}$ & $2.00 \mathrm{~mm}$ & $\begin{array}{l}\text { Top quality UK track, 225km } / \mathrm{h} \\
(140 \mathrm{mph}), \text { an example of best intercity } \\
\text { track }\end{array}$ \\
\hline $\begin{array}{c}\text { Track } \\
270\end{array}$ & $\begin{array}{c}270 \\
\mathrm{~km} / \mathrm{h}\end{array}$ & $4 \mathrm{~km}$ & $1.04 \mathrm{~mm}$ & $1.81 \mathrm{~mm}$ & $\begin{array}{l}\text { Top quality German ICE track, 270km/h } \\
(170 \mathrm{mph})\end{array}$ \\
\hline
\end{tabular}

\subsection{Power Regenerating Damper}

With the rapidly increases demands of large energy for the rail transport, the development of recoverable energy in rail vehicle suspension systems are an effective method to meet the purpose of energy saving of the trend of future regenerative dampers in rail vehicle. There are many designs in development for regenerative suspension or dampers. Amongst them, regenerative electro-hydraulic damper is more potential due to its inherent design benefits of the unidirectional-flow with low inertia loss, reliable hydraulic transmission and high regeneration efficienc [43-45]. As shown in Fig. 3 and Fig. 4, a schematic design of a PRD is proposed which consist of a double acting hydraulic cylinder, a hydraulic rectifier (four check valve arrangement), a hydraulic motor, and a generator.

The hydraulic cylinder is designed to have four ports, which are distributed at both sides of the cylinder body, four check valves have been connected which act as a hydraulic rectifier. Through rectification, the hydraulic fluid during the bounce and rebound motions pass through the hydraulic motor in one direction. The hydraulic motor is directly coupled to the generator, and driven by the pressurised flow. The hydraulic motor converts the linear motion 
of the primary suspension system into rotary motion by fluid transfer, and then the succeeding rotation of the hydraulic motor drives the generator to generate electricity [33].

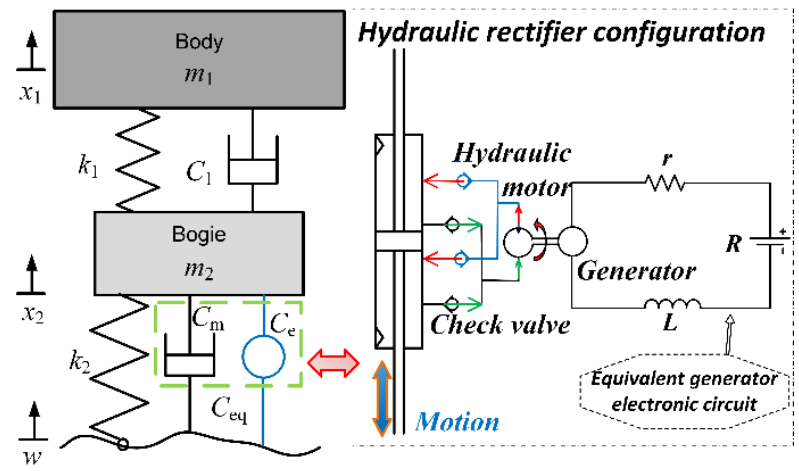

Fig. 3 Simplified diagram of the suspension systems and PRD ('Parallel - Case 1')

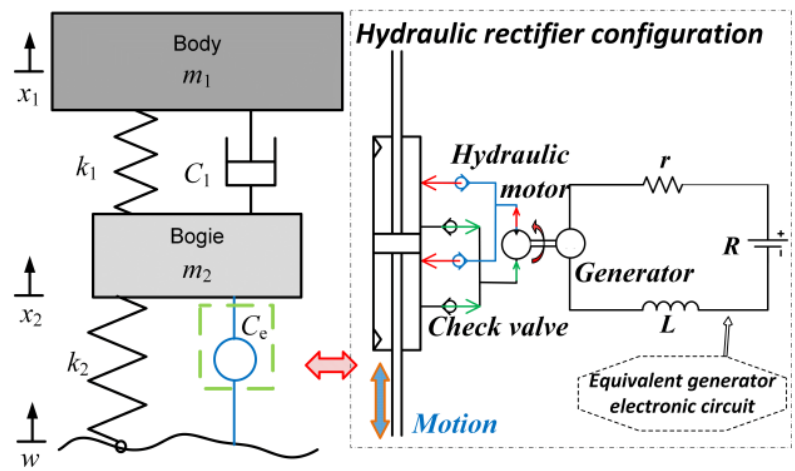

Fig. 4 Simplified diagram of the suspension systems and PRD ('Series - Case 2')

Fig. 3 and Fig. 4 show a simplified primary suspension system equipped with the PRD in 'Case 1' and 'Case 2' which can be executed with the standard fluid viscous damper in parallel and series connections in primary suspension system. It can be noted that the PRD can provide desirable damping by adjusting electrical load $\mathrm{R}$ to reach an appreciate damping whilst recovering power for energy saving.

Table 4 Values of key parameters of the PRDs

\begin{tabular}{ccc}
\hline Symbol & Value & Unit \\
\hline$A_{m}$ & $1.27 \times 10^{-4}$ & $\mathrm{~m}^{2}$ \\
$D_{m}$ & $(6.35 \mathrm{~mm}$ radius $)$ & $(\mathrm{mm})$ \\
$k_{T}$ & 8.2 & $c c\left(\times 10^{-6} \mathrm{~m}^{3}\right)$ \\
$k_{V}$ & 0.925 & $\mathrm{Nm} / \mathrm{A}$ \\
$\eta_{v}$ & 0.925 & $\mathrm{~V} /(\mathrm{rad} / \mathrm{s})$ \\
$\eta_{m}$ & 92 & $\%$ \\
$r$ & 95 & $\%$ \\
$R($ Case 1$)$ & 10 & $\Omega$ \\
\hline
\end{tabular}


Using a PRD, energy from the track roughness induced vibrations can be converted into recoverable energy which can be stored in a battery/cell for further use, and an appropriate damping coefficient can be provided by adjusting the electrical load which can be further developed for semi-active control or self-powered force control.

Based on a typical passenger rail vehicle model, PRD and measured track data, some evaluation criteria for ride comfort, running safety, potential power and regenerated power, which can be met by primary suspension system, is presented. The evaluation is dependent on the potential power, recoverable power, power efficiency, wheel-rail contact forces and accelerations of car body and bogies. This study is intended to give a design guideline for the use of a regenerative primary damper; the primary damper in a rail vehicle is not only for power generation, but also the dynamic performance in terms of running safety and passenger comfort.

In the proposed system, the equivalent damping of primary damper and PRD can be written as:

$$
C_{e q}=C_{m}+C_{e}
$$

where $C_{e q}$ is the equivalent damping coefficient of the primary damper, $C_{m}$ is the viscous damping coefficient, $C_{e}$ is the electric damping coefficient (controllable damping coefficient), respectively. The electric damping coefficient is [46]:

$$
C_{e}=\left(\frac{2 \pi A_{m}}{D_{m}}\right)^{2}\left(\frac{k_{T} k_{V}}{r+R}\right) \frac{\eta_{v}}{\eta_{m}}
$$

where $A_{m}$ is the area of hydraulic cylinder cross-sectional area, $D_{m}$ is the displacement of the hydraulic motor, $k_{T}$ is the torque constant coefficient, $k_{V}$ is electromotive voltage constant coefficient, $r$ is the internal resistance of the generator, $R$ is the external load, $\eta_{v}$ and $\eta_{m}$ are the volumetric and mechanical efficiency of the hydraulic motor. The hydraulic motor flow rate is given by:

$$
Q_{m}=A_{m} v
$$

where $v$ is the vertical velocity of the primary damper. The motor/generator shaft speed can be calculated by:

$$
\omega_{m}=\frac{2 \pi Q_{m} \eta_{v}}{D_{m}}
$$


The generator used in the PRD should be mechanically simple for ease of functionality and operability. Therefore, an equivalent DC permanent magnetic generator has been modelled and embedded into the primary suspension system in this study. Electromotive force (EMF) is highly dependent on the generator armature speed and field current.

The electromotive force (EMF) $E$ and the instantaneous electrical current $I$ are given by:

$$
E=k_{V} \omega_{m} \text { and } I=\frac{E}{R+r}
$$

and regenerated power is the power that recovered by the PRD for reuse, which can be calculated as:

$$
P_{e}=I^{2} R
$$

The input power obtaining from the vibrational excitation is defined as the potential recoverable, and can be given by:

$$
P_{i n s}=c_{e q} v^{2}
$$

and the average potential power is:

$$
P_{a v}=\frac{1}{T} \int_{0}^{T} C_{e q} v^{2} d t
$$

where $T$ is the time end and $d t$ is the time interval. Table 3 shows the model-related component parameters of the PRD such as the hydraulic rectifier and generator specifications.

According to Equations (3) to (8), the power regeneration efficiency is given by:

$$
\eta_{e f f}=\frac{P_{e}}{P_{a v}}=\frac{2 \pi T A_{m} v \eta_{v} \omega_{m}}{D_{m}(R+r) \int_{0}^{T}\left(C_{m}+C_{e}\right) v^{2} d t}
$$

Equation (2) represents the controllable damping coefficient of the PRD and shows that damping is dependent on electrical load. According to Equation (2), it indicates that the damping coefficient can be adjusted in a large range by controlling the external electrical load or specific charge circuit. In such a prediction, the electrical damping coefficient (controllable damping coefficient) is decreased with the increase of the electrical load.

Fig. 5 shows that electrical damping can act as additional damping/ alternative damping when applied to the primary suspension system. This allows adjustment of the damping whilst recovering power for energy saving. In Fig. 5(a), a $1 \Omega$ electrical load can provide a damping coefficient of around $710 \mathrm{Ns} / \mathrm{m}$, which is approximate to $1 / 6$ of the viscous damping of existing primary damper whilst a larger electrical load over $50 \Omega$ offers less additional damping coefficient, which approaches to zero. In addition, the damping coefficient of the PRD- 'Case 2' altered with the electrical loads has been shown in Fig. 5(b). A $0.5 \Omega$ electrical 
load is equivalent to a damping coefficient of around $5200 \mathrm{Ns} / \mathrm{m}$, which is enough for a generic passenger rail vehicle. Therefore, the PRD can be adjusted in a large range of by controlling the external electrical loads. The PRD is also possible to produce required damping coefficient to replace the conventional primary vertical damper.
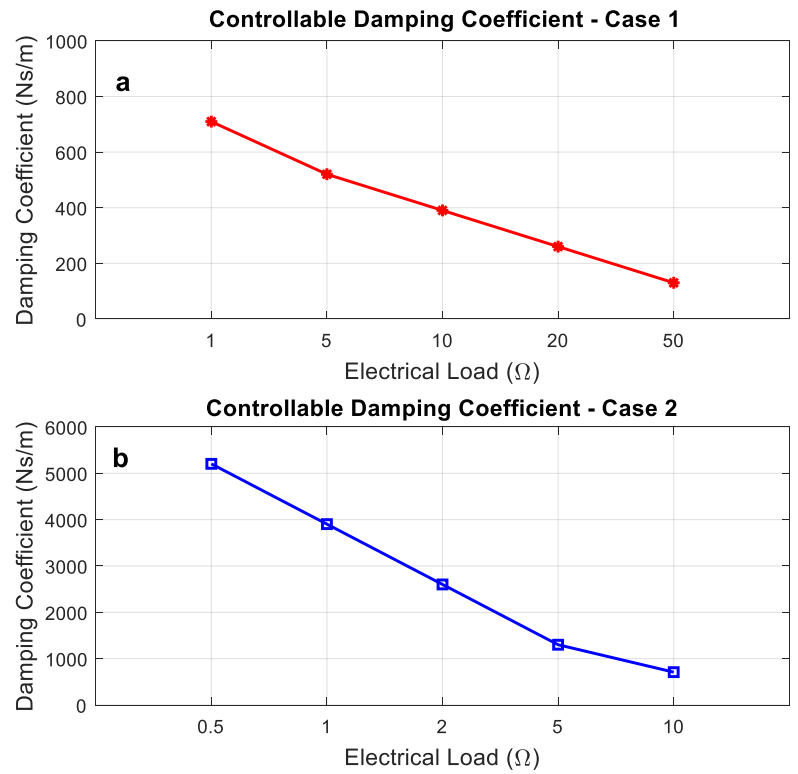

Fig. 5 Electrical damping coefficient with different electrical loads - 'Case 1' and 'Case 2'

\subsection{Ride Comfort}

The suspension system of modern passenger rail vehicles ensures the ride quality for the passengers and staff over different track irregularities. The suspension system acts as a key component to suppress the track-induced vibration therefore its dynamic performance has a significant influence on the ride quality.

According to the BS EN 12299-2009 standard of ride comfort-railway applications [47], the method involves filtering the carbody acceleration time history [output in longitudinal $\left(a_{X P 95}^{W_{d}}\right)$, lateral $\left(a_{Y P 95}^{W_{d}}\right)$ and vertical $\left.\left(a_{Z P 95}^{W_{d}}\right)\right]$ calculating the RMS for 5 second intervals and determining the $95^{\text {th }}$ percentile of the 5 second RMS acceleration values. The $95^{\text {th }}$ percentile accelerations were then entered in to the following equation to determine the mean ride comfort index:

$$
N_{M V}=6 \sqrt{\left(a_{X P 95}^{W_{d}}\right)^{2}+\left(a_{Y P 95}^{W_{d}}\right)^{2}+\left(a_{Z P 95}^{W_{b}}\right)^{2}}
$$

According to the particular interest of the ride comfort indices NMV, the standard of ride comfort indications defined in Table 5 to provide an obvious criterion: 
Table 5 NMv evaluation scales - ride comfort [36]

\begin{tabular}{cc}
\hline \multicolumn{2}{c}{ Scale for the $\boldsymbol{N}_{\boldsymbol{M V}}$ Comfort Index } \\
\hline$N_{M V}<1.5$ & Very comfortable \\
$1.5 \leq N_{M V} \leq 2.5$ & Comfortable \\
$2.5 \leq N_{M V} \leq 3.5$ & Medium \\
$3.5 \leq N_{M V} \leq 4.5$ & Uncomfortable \\
$N_{M V} \geq 4.5$ & Very uncomfortable \\
\hline
\end{tabular}

\subsection{Running Safety}

Running safety is determined by the wheel-rail contact forces (lateral and vertical) which are exchanged between the wheel and the rail, as shown in Fig. 6. One of the main risks of derailment is realised when a there is large lateral force and a low vertical force acting between the wheel and the rail allowing the wheel flange to climb up the rail gauge face rapidly resulting in a derailment. Therefore, the safety requirements on the wheel-rail contact performance of rail vehicle needs are considered as a key performance.

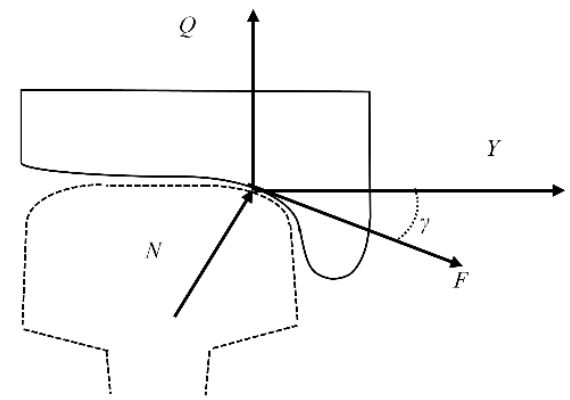

Fig. 6 Wheel-rail contact forces: Y (lateral force), Q (vertical force), N (normal force) and F (lateral rolling friction force)

The wheel-rail contact force ratio can be calculated in term of the lateral force and vertical force at various driving speeds and different electrical loads. Based on the Nadal criterion [48] and GM/RT2141 [49] which shall nowhere exceed 1.2, it can be shown as follows:

$$
\frac{Y}{Q}<\frac{\tan \alpha-\mu}{1+\mu \tan \alpha},(Y / Q)_{2 m} \leq 1.2
$$

where $\mu$ is the friction coefficient at the contact point and $\alpha$ is the maximum flange contact angle.

\section{Analysis, Results and Discussion}


To evaluate the ride comfort, running safety, potential power and regenerated power, the rail vehicle primary suspension system developed in Section 2.3 was used with different vehicle running speeds, track cases and electrical loads.

\subsection{Ride Comfort and Running Safety}

In order to assess the comparative ride performance under different operating conditions, simulations were undertaken at constant speed using approximately of $30 \mathrm{~km}$ of measured track geometry selected to be representative of the track seen by the modelled passenger rail vehicle. The simulation conditions can be summarised as follows:

Vehicle type: a generic $33 \mathrm{t}$ passenger vehicle

Wheel-rail contact: New P8 wheel, New 56E1 rail

Track cases: $\approx 30 \mathrm{~km}$ measured track geometry

Wheel-rail Friction coefficient: 0.32

Running speeds: $25,50,75,100 \mathrm{mph}$ (with $1 \Omega$ electrical load)

'Case 1': 1, 5, 10, 20, $50 \Omega$ (100mph running speed)

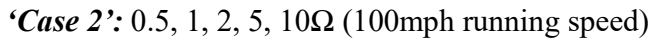

Accelerations were predicted on the vehicle body at floor level above the leading and trailing bogie pivots and at the body centre. These were the weighted according to the lateral $\left(W_{d}\right)$ and vertical $\left(W_{b}\right)$ passenger comfort filters contained in Euro-Norm EN 12299:2009 [47]. The mean ride comfort of body centre, pivot 1 and pivot 2 were calculated with different running speeds and electrical loads which is shown in Table 6 and 7.

Table 6 Ride comfort assessment at different vehicle speeds and electrical loads

\begin{tabular}{|c|c|c|c|c|c|c|c|}
\hline \multicolumn{4}{|c|}{ Case 1} & \multicolumn{4}{|c|}{ Case 2} \\
\hline \multicolumn{4}{|c|}{$\begin{array}{l}95^{\text {th }} \text { Percentile Weighted RMS Acceleration } \\
\text { (Mean Ride comfort) }\end{array}$} & \multicolumn{4}{|c|}{$\begin{array}{l}95^{\text {th }} \text { Percentile Weighted RMS Acceleration } \\
\text { (Mean Ride comfort) }\end{array}$} \\
\hline $\begin{array}{l}\text { Running Speed } \\
\text { (Load: } 1 \Omega \text { ): }\end{array}$ & $\begin{array}{l}\text { Body } \\
\text { Centre }\end{array}$ & $\begin{array}{c}\text { Pivot } \\
1\end{array}$ & $\begin{array}{c}\text { Pivot } \\
2\end{array}$ & $\begin{array}{l}\text { Running Speed } \\
\text { (Load: } 1 \Omega \text { ): }\end{array}$ & $\begin{array}{l}\text { Body } \\
\text { Centre }\end{array}$ & $\begin{array}{c}\text { Pivot } \\
1\end{array}$ & $\begin{array}{c}\text { Pivot } \\
2\end{array}$ \\
\hline $25 \mathrm{mph}$ & 0.6285 & 0.8265 & 0.9730 & $25 \mathrm{mph}$ & 0.6229 & 0.8158 & 0.9596 \\
\hline $50 \mathrm{mph}$ & 0.6924 & 1.3738 & 1.1074 & $50 \mathrm{mph}$ & 0.6790 & 1.3459 & 1.0770 \\
\hline $75 \mathrm{mph}$ & 0.8178 & 1.3696 & 1.4633 & $75 \mathrm{mph}$ & 0.8045 & 1.2948 & 1.4520 \\
\hline $100 \mathrm{mph}$ & 1.0422 & 1.7284 & 2.1450 & $100 \mathrm{mph}$ & 1.0401 & 1.7243 & 2.1318 \\
\hline
\end{tabular}

Table 7 Ride comfort assessment at different vehicle speeds and electrical loads

\begin{tabular}{cccc}
\hline \multicolumn{4}{c}{ Original Primary Damper } \\
\hline \multicolumn{4}{c}{ 95 ${ }^{\text {th }}$ Percentile Weighted RMS Acceleration } \\
(Mean Ride comfort) \\
\hline Running Speed: & Body Centre & Pivot 1 & Pivot 2 \\
\hline 25mph & 0.6285 & 0.8265 & 0.9730 \\
$50 \mathrm{mph}$ & 0.6924 & 1.3738 & 1.1074 \\
\hline
\end{tabular}




\begin{tabular}{cccc}
\hline $75 \mathrm{mph}$ & 0.8178 & 1.3696 & 1.4633 \\
$100 \mathrm{mph}$ & 1.0422 & 1.7284 & 2.1450 \\
\hline
\end{tabular}

The mean ride comfort is generally worse with the increase of the vehicle running speed at body centre, pivot 1 and pivot 2 . In the worst case (100mph), the mean ride comfort $N_{M V}$ at pivot 2 are up to 1.68 but it is still fairly comfortable for the human vibration sensitivity. In addition, it confirms that the ride performance of the 'Case 1' is not tied on the electrical load in electric circuit of primary suspensions but it is proportional to the increase of the electrical load in the 'Case 2' at speed of 100mph. For comparison, the RMS accelerations of the original primary vertical damper has also been analysed and shown in Table 6 and 7. It is clear that the damping coefficient of these three cases applied using the values Case $1=$ $4889 \mathrm{Ns} / \mathrm{m}$, Case $2=3903 \mathrm{Ns} / \mathrm{m}$ and Original $=4179 \mathrm{Ns} / \mathrm{m}$ in terms of the values in Figure 5 . However, the mean ride comfort was affected by the value of the equivalent damping coefficient, which can be altered by the electrical load in Case 1 and 2. It indicates that the less controllable damping coefficient in Case 2 can provide slightly better ride comfort, particularly at lower electrical load, and this phenomenon is also confirmed in Table 8 . In Case 1, the controllable damping coefficient

Table 8 Ride comfort assessment at different electrical loads

\begin{tabular}{|c|c|c|c|c|c|c|c|}
\hline \multicolumn{4}{|c|}{ Case 1} & \multicolumn{4}{|c|}{ Case 2} \\
\hline \multicolumn{4}{|c|}{$\begin{array}{l}\text { 95 } 5^{\text {th }} \text { Percentile Weighted RMS Acceleration } \\
\text { (Mean Ride comfort) }\end{array}$} & \multicolumn{4}{|c|}{$\begin{array}{l}\text { 95 }^{\text {th }} \text { Percentile Weighted RMS Acceleration } \\
\text { (Mean Ride comfort) }\end{array}$} \\
\hline $\begin{array}{l}\text { Load Resistance } \\
\text { (Speed: } \\
\text { 100mph) }\end{array}$ & $\begin{array}{l}\text { Body } \\
\text { Centre }\end{array}$ & $\begin{array}{c}\text { Pivot } \\
1\end{array}$ & $\begin{array}{c}\text { Pivot } \\
2\end{array}$ & $\begin{array}{l}\text { Load Resistance } \\
\text { (Speed: } \\
\text { 100mph) }\end{array}$ & $\begin{array}{l}\text { Body } \\
\text { Centre }\end{array}$ & $\begin{array}{c}\text { Pivot } \\
1\end{array}$ & $\begin{array}{c}\text { Pivot } \\
2\end{array}$ \\
\hline $1 \Omega$ & 1.0422 & 1.7284 & 2.1450 & $0.5 \Omega$ & 1.0401 & 1.7243 & 2.1318 \\
\hline $5 \Omega$ & 1.0422 & 1.7284 & 2.1450 & $1 \Omega$ & 1.0442 & 1.7367 & 2.1484 \\
\hline $10 \Omega$ & 1.0422 & 1.7284 & 2.1450 & $2 \Omega$ & 1.0507 & 1.7580 & 2.1702 \\
\hline $20 \Omega$ & 1.0422 & 1.7284 & 2.1450 & $5 \Omega$ & 1.0597 & 1.8010 & 2.2202 \\
\hline $50 \Omega$ & 1.0422 & 1.7284 & 2.1450 & $10 \Omega$ & 1.0668 & 1.8705 & 2.2781 \\
\hline
\end{tabular}

Next, simulations were carried out to examine the resistance of the proposed vehicle model to low speed flange climbing derailment according to requirements of GM/RT2141 [49]. The following conditions were considered:

Wheel-rail friction coefficient: 0.32

Running speed: Trundle $(2 \mathrm{~m} / \mathrm{s})$

Track cases: see the following Table 9.

Table 9 Low speed flange climb track cases

\begin{tabular}{ccccc}
\hline $\begin{array}{c}\text { Radius } \\
(\mathrm{m})\end{array}$ & $\begin{array}{c}\text { Cant } \\
(\mathrm{mm})\end{array}$ & $\begin{array}{c}\text { Gauge Widening } \\
(\mathrm{mm})\end{array}$ & $\begin{array}{c}\text { Transition } \\
\text { Length }(\mathrm{m})\end{array}$ & $\begin{array}{c}\text { Distance from start of run-off } \\
\text { transition to centre of dip }\end{array}$ \\
\hline 90 & 25 & 19 & 7.5 & $\begin{array}{c}\text { Om (Top) } \\
7.5 \mathrm{~m} \text { (Bottom) }\end{array}$ \\
\hline
\end{tabular}




\begin{tabular}{ccccc}
\hline 150 & 100 & 13 & 30 & $6 \mathrm{~m}$ (Top) \\
200 & 150 & 6 & 45 & $16.883 \mathrm{~m}$ (Bottom) \\
& & & $6 \mathrm{~m}$ (Top) \\
& & & $16.883 \mathrm{~m}$ (Bottom) \\
\hline
\end{tabular}

Table 10 shows the ratio of lateral to vertical force (Y/Q) for the leading wheest outer wheel using different curve radii at $1 \Omega$. In all case predicted Y/Q remains below both the Nadal limit of 1.2 and the 99.85 percentile limit of 0.8 . The results of the maximum Y/Q are slight different between 'Case 1' and 'Case 2'. Therefore, based on the results of the Weighted RMS acceleration and Y/Q, it can be summarised that the applied PRD has a slight influence on ride comfort and running safety but the ride comfort and running safety are highly reliant on the vehicle running speed, track irregularity and track design.

Table $10 \mathrm{Y} / \mathrm{Q}$ low speed flange climb case at $1 \Omega$ electrical load

\begin{tabular}{|c|c|c|c|c|}
\hline \multicolumn{2}{|c|}{ Track Cases } & Original & Case $1(1 \Omega)$ & Case $2(1 \Omega)$ \\
\hline Radius & Transition* & $\begin{array}{c}\text { Max. } \\
\text { Y/Q }(<1.2)\end{array}$ & $\begin{array}{c}\text { Max. } \\
\text { Y/Q }(<1.2)\end{array}$ & $\begin{array}{c}\text { Max. } \\
\text { Y/Q }(<1.2)\end{array}$ \\
\hline 90 & Bottom & 0.714 & 0.714 & 0.714 \\
\hline 90 & Top & 0.683 & 0.699 & 0.699 \\
\hline 150 & Bottom & 0.605 & 0.605 & 0.605 \\
\hline 150 & Top & 0.761 & 0.760 & 0.760 \\
\hline 200 & Bottom & 0.715 & 0.726 & 0.723 \\
\hline 200 & Top & 0.676 & 0.676 & 0.675 \\
\hline
\end{tabular}

*Distance from start of run-off transition to centre of dip

\subsection{Effect of Running Speed}

Track input is the key impact of a rail vehicle excitation, but the detailed relationship between the track differences/running speeds and the power capability was not discussed in previous research works. According to the PRD and rail vehicle models, the force-velocity loops and power outputs at various speeds and tracks are obtained and shown in Fig. 7 and Fig. 8.

Firstly, vehicle running speeds are modelled as the first influencing factor on power capability and damping characteristic. With the damping recalculation in Section 2.3, the equivalent damping coefficient of the primary damper can be found in Fig. 9, and the predicted results show the trend of damping coefficient and damping force which are degraded with the growth of the vehicle speed, and the damping force highly depends on the surface geometry of the track. It is clear that the potential power and increase with various vehicle running speeds ranging from $25 \mathrm{mph}$ to $125 \mathrm{mph}$ with an increment of $25 \mathrm{mph}$. However, it can be summarised that vehicle running speed is the key factor for the capability of power regeneration in proposed primary suspension systems, and the higher running speeds can provide a larger flow rate of the hydraulic motor which can drive a faster rotating speed of the DC generator and finally produce a larger damping force and a higher power 
outputs. Therefore, the running speed and track case will be considered to develop the design and the practical use of a power regenerative damper.

The damping forces between 'Series' and 'Parallel' cases at different running speeds are shown in Fig. 7(a) and (c). From these results we can see that the damping characteristics have similar force-velocity loops at the low running speeds (25mph to $100 \mathrm{mph}$ ). At speed of $125 \mathrm{mph}$, according to the impact of bump stop in conventional primary vertical damper, equivalent damping force (viscous and controllable damping forces) in parallel case (Case 1) tends to be stable when the peak value is over 2100 N. For series case (Case 2), the designed RPD replaced conventional damper to provide the controllable damping force, and the peak damping force decreases with the increase of the value of external electrical load. It indicates that the series configuration has its benefit for providing wide range of controllable damping force by adjusting electrical load. It also reveals that PRD brings a great construability for a self-powered and semi-active primary suspension.
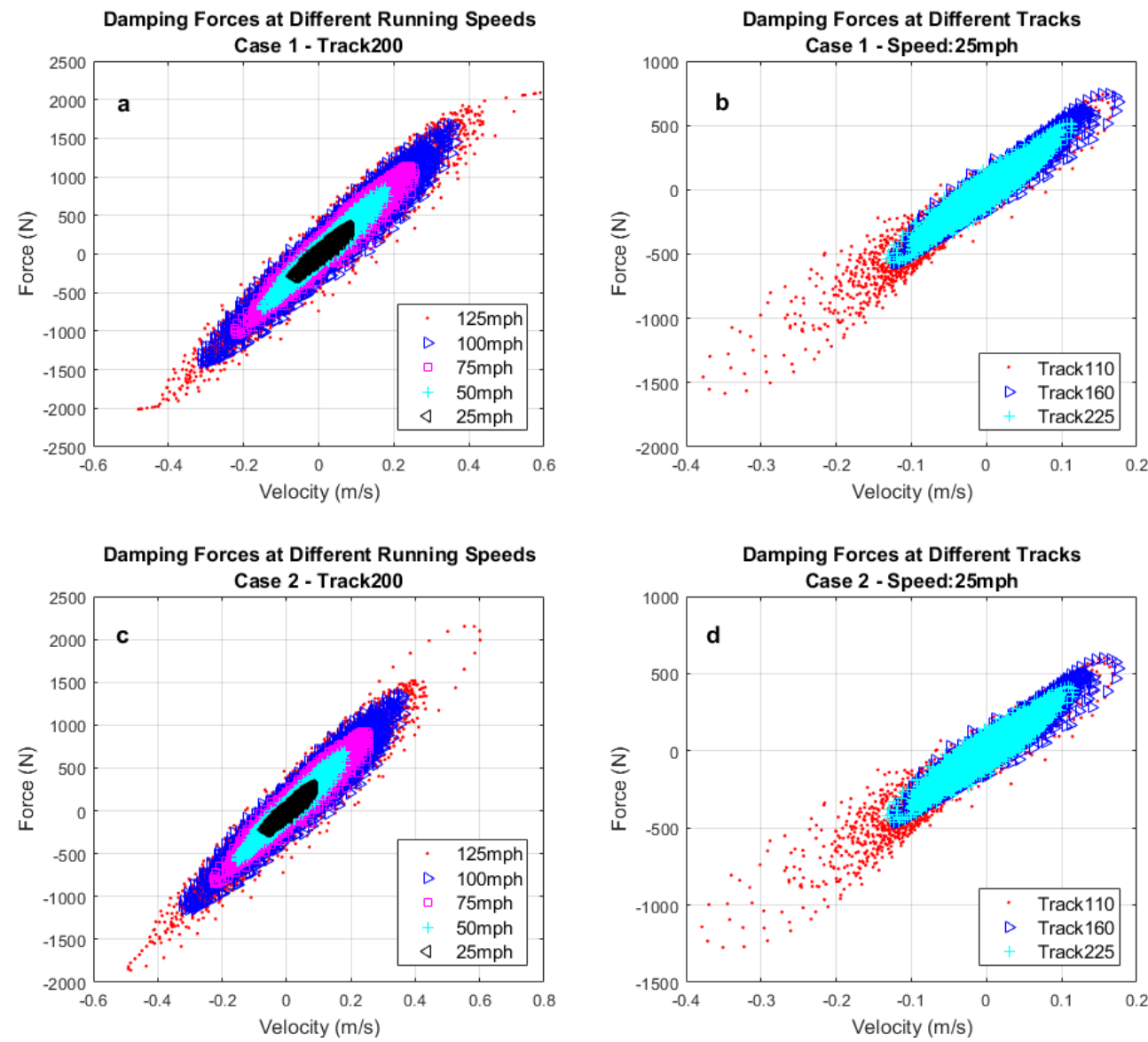

Fig. 7 Force-Velocity loops in 'Case 1' and 'Case 2' at various running speeds and track cases

Fig. 8 shows that the average of the potential power and regenerated power are predicted at different measured tracks with the vehicle running speed increased from $25 \mathrm{mph}$ to $125 \mathrm{mph}$ 
with a $1 \Omega$ electrical load in both cases. The power in values are mildly increased with the growth of vehicle speeds, and the faster running speed can produce more excitation events and thus to provide more potential power and regenerated power but the power regeneration efficiencies have no obvious increases which are around $1.2 \%$ in two applied cases.

At a running speed of $100 \mathrm{mph}$, a higher potential power of $73.17 \mathrm{~W}$ and $59.33 \mathrm{~W}$ can be obtained in 'Case 1' and 'Case 2' when a rail vehicle runs on typical 'Track160'. It clearly shows that the regenerated power in primary suspension systems has a great potential to recharge the electronic equipment of vehicle or achieve the regenerative capability. A peak power of $26.06 \mathrm{~W}$ can be regenerated in 'Case 2' when the vehicle travels at $125 \mathrm{mph}$ on a mainline UK track ('Track160'). According to the configuration of Case 1 (Parallel), most of the potential power has been dissipated in the form of heat by the conventional damper and PRD to attenuate the vibration which is produced by track-related excitation, and only a small amount of power can be regenerated by the PRD. By contrast, in Case 2 (Series) the track-related excitation directly acts on the PRD to maximise its regenerative capability whilst providing needed consistent damping force for the suspension system.
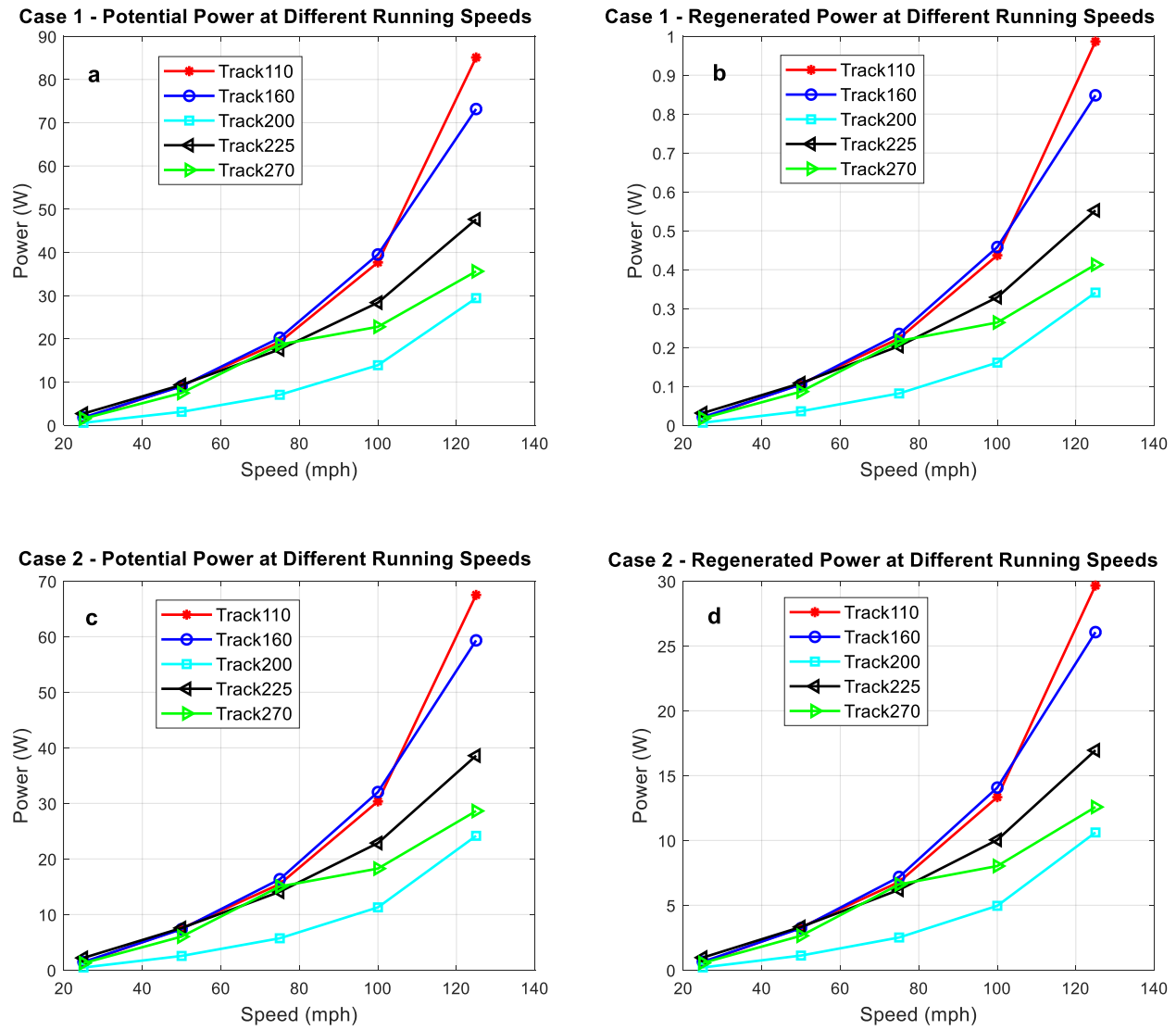

Fig. 8 Potential power and regenerated power at different running speeds and tracks in 'Case 1' and 


\subsection{Effect of Electrical Load}

The following analysis will explore the characteristics of the potential power, regenerated power and power efficiency at various electrical loads. In Fig. 9(a), the increase of the electrical load has no significant effect on the potential power of the primary damper at 'Case 1 ' but the potential power reduces along with the value of electrical load growth in Fig. 9(c).

Due to the increase of the controllable damping coefficient of the series configuration (Case 2 - without viscous damper), a considerable amount of regenerated power can be produced, as shown in Fig. 9(d), which is also beneficial to improving the regenerative efficiency of power on PRD. In Fig. 9(b) and (d), it is clear that the regenerated power of Case 1 is significantly smaller that of the Case 2 because a large amount of power was dissipated by the hydraulic system of conventional damper. In addition, the regenerative efficiency of the PRD in Case 2 increases sharply with an increase in electrical load whereas the regenerative efficiency of the PRD in Case 1 stays at a pretty low level which is between $1 \%$ and $4 \%$.
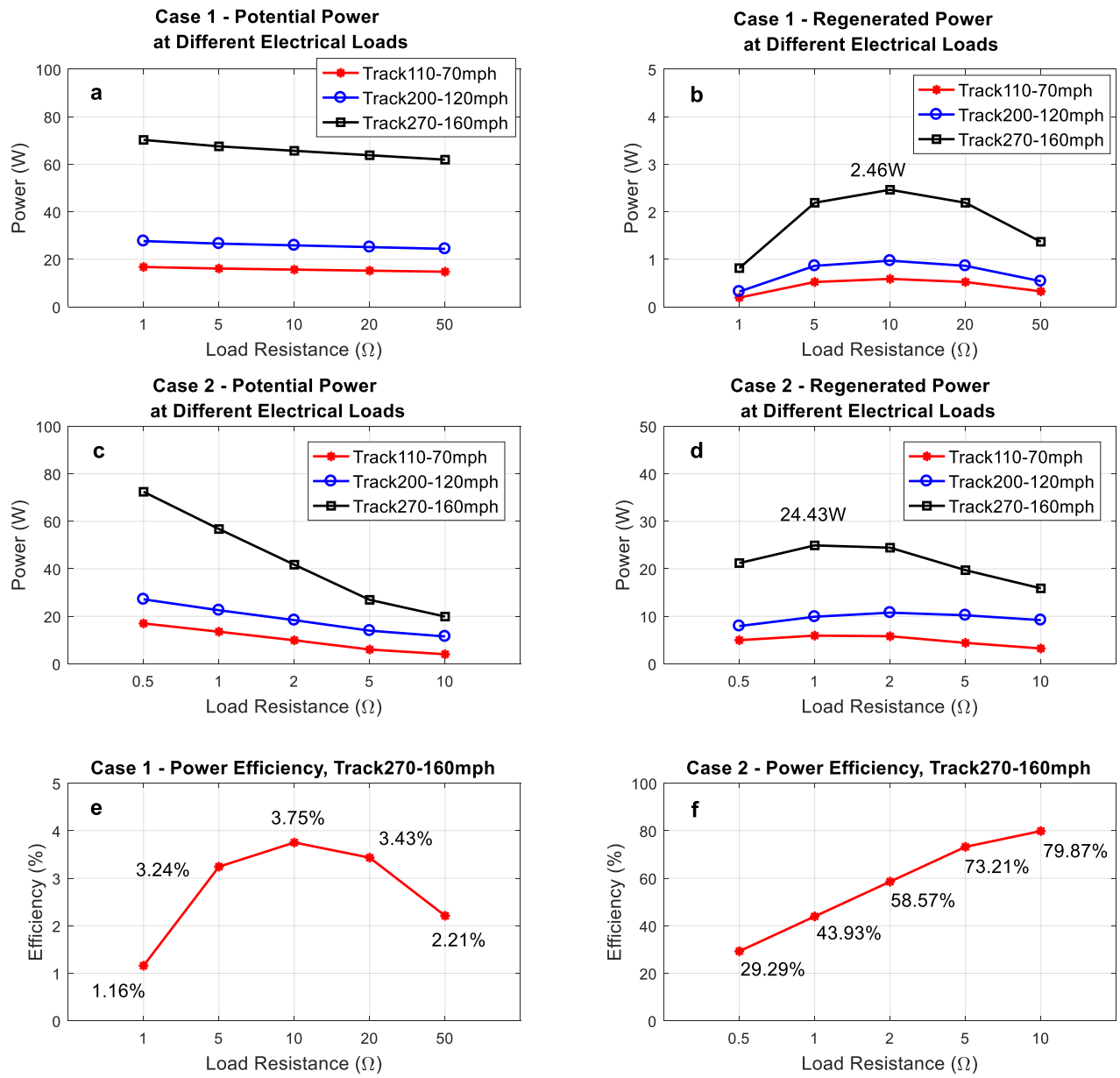
Fig. 9 Potential power, Power regenerated power and power efficiency at different electrical loads in 'Case 1' and 'Case 2'

As shown in Fig. 9(b) and (d), the maximum regenerated power is occurred at $1 \Omega$ electrical load, and the maximum efficiency of $3.75 \%$ in 'Case 1' (Fig. 9(e)), which is identical the internal load resistance of the generator. This indicates that the optimal power regeneration with maximum regenerating efficiency can be reached through the impedance matching. In Case 2, power efficiency is increasing with the degradation of the damping coefficient (the growth of the external electrical load). As shown in Fig. 9(f), the peaks of power can be regenerated using the load resistance of $1 \Omega$ in each of running condition (trackspeed) but a maximum efficiency of $79.87 \%$ is obtained at $10 \Omega$ electrical load (which provides the minimum damping coefficient for the primary suspension system), occurring in response to a predefined top quality German ICE track with a $160 \mathrm{mph}$ vehicle speed. Thus, it can be summarised that the series configuration can effectively improve the capability of power regeneration whilst providing a suitable damping characteristic for primary suspension system.

\section{Conclusions}

Power regeneration from railway vehicle that operate on irregular tracks and result in track-induced vibrations is an attractive filed of vehicle dynamics. In this paper, it attempts to capture and harvest the energy loss owing to the track-induced vibration from the primary suspension system based on more realistic measured tracks. In this way, power regenerating dampers (PRDs) was developed using hydraulic-electro configuration and configured in two ways, with and without a viscous damper (Parallel and Series). A detailed model of typical UK passage vehicle with PRDs was modelled to evaluate the potential power and regenerated power of the rail vehicle primary suspensions and the influence that such a system had on the performance of ride quality and running safety was investigated. For the proposed PRD, the results of average power and efficiency were analysed at different vehicle running speed, track quality and electrical loads. The regenerated power can be reused to meet the requirement of the needed power for vehicle semi-active suspension or suspension electronic components.

The findings showed that:

According to the results, the overall primary suspension system using the power regenerating damper in parallel and series connections delivered similar ride comfort and running safety compared the conventional primary suspension system.

The increment of external electrical load and running speed also has no significant effect on ride comfort and running safety of a rail vehicle. 
The equivalent damping coefficient highly depends on the electrical loads, and the results have shown that the better track quality can produce less exercitation events and thus to provide less peak damping force.

Using the measured track data as inputs, the potential power output of approximately $2-85 \mathrm{~W}$ is available for a single primary damper of a typical passenger rail vehicle at $125 \mathrm{mph}$ on a poorer quality low speed track, and the increase of the vehicle speed would be a key factor that allows positive action to the power regeneration significantly.

According to the design of the power regenerating damper, the maximum efficiency $(3.75 \%)$ of the Case 1 at $10 \Omega$, which is identical to the internal resistance of the generator. In Case 2, the increase of the external electrical load has benefit on the power efficiency which is up to $79.87 \%$ at $10 \Omega$, but the maximum power $(24.43 \mathrm{~W}$ ) can be regenerated at $1 \Omega$ (which is identical to the internal resistance).

It can be summarised that the series configuration can effectively improve the capability of power regeneration whilst providing a suitable damping characteristic for primary suspension system. It can also be treated as a semi-active regenerative damper by controlling electrical load to meet the requirements of different suspension systems. It also indicates that the power regenerating damper has a great potential to replace the conventional primary damper.

\section{Funding}

The author(s) is grateful for the financial support provided by the Sichuan Science and Technology Program (2019JDRC0081).

\section{References}

1. Yu F, Cao M, Zheng X. Research on the feasibility of vehicle active suspension with energy regeneration. Journal of Vibration and Shock, 2005, 24:27-30.

2. Karnopp D. Power requirements for vehicle suspension systems. Vehicle System Dynamics, 1992, 21:65-71.

3. Yu C, Wang W, Wang Q. Analysis of energy-saving potential of energy regenerative suspension system on hybrid vehicle. Journal of Jilin University (Engineering and Technology Edition), 2009, 39:841-5.

4. Liang J, Shao C. Research on an energy-regenerative active suspension for vehicles. Vehicle \& Power Technology, 2008, 17.

5. Mossberg J, Anderson Z, Tucker C. Recovering Energy from Shock Absorber Motion on Heavy Duty Commercial Vehicles, SAE International in United States, 2012; 
6. Matamoros-Sanchez AZ. The use of novel mechanical devices for enhancing the performance of railway vehicles. Dissertation for the Doctoral Degree. Loughborough, UK: Loughborough University; 2013.

7. Zheng P, Wang R, Gao J, Zhang X. Parameter Optimisation of Power Regeneration on the Hydraulic Electric Regenerative Shock Absorber System. Shock and Vibration, 2019.

8. Zuo L, Zhang P-S. Energy harvesting, ride comfort, and road handling of regenerative vehicle suspensions. Journal of Vibration and Acoustics, 2013, 135:011002.

9. Energy-harvesting shock absorber that increases fuel efficiency wins R\&D 100 award, phys.org/news/2011-07-energy-harvesting-absorber-fuel-efficiency-award.html

10. Zhang J, Peng Z, Zhang L, Zhang Y. A review on energy-regenerative suspension systems for vehicles. Proceedings of the World Congress on Engineering. London, UK, 2013, p. 1889-92.

11. Zheng P, Wang R, Gao J. A Comprehensive Review on Regenerative Shock Absorber Systems. Journal of Vibration Engineering \& Technologies, 2019.

12. Wendal G, Stecklein G. A Regenerative Active Suspension System. SAE Publication SP861, Paper No 910659, 1991,129-135.

13. Fodor MG, Redfield RC. The variable linear transmission for regenerative damping in vehicle suspension control. American Control Conference, 1992, p. 26-30.

14. Jolly MR, Margolis DL. Regenerative systems for vibration control. Journal of Vibration and Acoustics, 1997, 119:208-15.

15. Aoyoma Y, Kawabate K, Hsegawa S, Kobari Y. Development of the Full Active Suspension by Nissan. SAE Technical Paper 901747, 1990.

16. Norisugu T. Energy saving of a pneumatic system (2). Energy regenerative control of a pneumatic drive system. Journal of Application to Active Air Suspension, Hydraulics \& Pneumatics, 1999, 38:1-4.

17. Stansbury J. Regenerative suspension with accumulator systems and methods. 2014.

18. Karnopp D. Permanent magnet linear motors used as variable mechanical dampers for vehicle suspensions. Vehicle System Dynamics, 1989, 18:187-200.

19. Ryba D. Semi-active damping with an electromagnetic force generator. Vehicle System Dynamics, 1993, 22:79-95.

20. Gupta A, Mulcahy TM, Hull JR. Electromagnetic shock absorbers. 2003.

21. Zuo L, Scully B, Shestani J, Zhou Y. Design and characterization of an electromagnetic energy harvester for vehicle suspensions. Smart Materials and Structures, 2010, 19:045003. 
22. Okada Y, Yonemura J, Shibata M. Regenerative control of moving mass type vibration damper. Proceedings of the 4th International Conference on Motion and Vibration Control (MOVIC), Zurich, Switzerland. 1998;85-90.

23. Suda Y, Nakadai S, Nakano K. Study on the self-powered active vibration control. Proceedings of the 4th International Conference on Motion and Vibration Control. 1998.

24. Cao M, Liu W, Yu F. Development on electromotor actuator for active suspension of vehicle. Chinese Journal of Mechanical Engineering, 2008, 44:224-8.

25. Zheng X, Yu F. Study on the potential benefits of an energy-regenerative active suspension for vehicles. SAE transactions, 2005, 114:242-5.

26. Li Z, Zuo L, Luhrs G, Lin L, Qin Y x. Electromagnetic energy-harvesting shock absorbers: Design, Modelling, and Road Tests. IEEE Transactions on Vehicular Technology, 2013, 62:1065-74.

27. Hayes RJ, Beno JH, Weeks DA. Design and testing of an active suspension system for a 2-1/2 ton military truck. SAE Technical Paper 2005, 01(1715), 2005;

28. Beno JH, Worthington MT, Mock JR. Suspension Trade Studies for Hybrid Electric Combat Vehicles. SAE Technical Paper 2005-01-0929, 2005;

29. Zhang Y, Zhang X, Zhan M, Guo K, Zhao F, Liu Z. Study on a novel hydraulic pumping regenerative suspension for vehicles. Journal of the Franklin Institute, 2015, 352:485-99.

30. Fang Z, Guo X, Xu L, Zhang H. Experimental study of damping and energy regeneration characteristics of a hydraulic electromagnetic shock absorber. Advances in Mechanical Engineering, 2013, 5:943528.

31. Li C, Tse PW. Fabrication and testing of an energy-harvesting hydraulic damper. Smart Materials and Structures, 2013, 22:065024.

32. Li C, Zhu R, Liang M, Yang S. Integration of shock absorption and energy harvesting using a hydraulic rectifier. Journal of Sound and Vibration, 2014, 333:3904-16.

33. Wang R, Gu F, Cattley R, Ball AD. Modelling, Testing and Analysis of a Regenerative Hydraulic Shock Absorber System. Energies, 2016, 9:386.

34. Sharma SK, Saini U, Kumar A. Semi-active Control to Reduce Lateral Vibration of Passenger Rail Vehicle Using Disturbance Rejection and Continuous State Damper Controllers. Journal of Vibration Engineering \& Technologies, 2019, 7:117-29.

35. Sharma SK, Kumar A. Disturbance rejection and force-tracking controller of nonlinear lateral vibrations in passenger rail vehicle using magnetorheological fluid damper. Journal of Intelligent Material Systems and Structures, 2018, 29:279-97. 
36. Sharma SK, Kumar A. Ride comfort of a higher speed rail vehicle using a magnetorheological suspension system. Proceedings of the IMechE, 2018, 232:32-48.

37. Sharma SK, Kumar A. Impact of Longitudinal Train Dynamics on Train Operations: A Simulation-Based Study. Journal of Vibration Engineering \& Technologies, 2018, 6:197-203.

38. Sharma SK, Kumar A. Impact of electric locomotive traction of the passenger vehicle Ride quality in longitudinal train dynamics in the context of Indian railways. Mechanics \& Industry, 2017, 18:222.

39. Sharma SK. Multibody analysis of longitudinal train dynamics on the passenger ride performance due to brake application. Proceedings of the IMechE. 2019; 233:266-79.

40. World Health Organization W. Global Status Report on Road Safety: Time for Action. World Health Organization; 2009.

41. Serco. VTISM Version 2.6.6 User Guide. 2014.

42. Vehicle Dynamics. Version 6.5. Resonate. VAMPIRE, 2016.

43. Wang R. Modelling, testing and analysis of a regenerative hydraulic shock absorber system. Dissertation for the Doctoral Degree, Huddersfield, UK: University of Huddersfield; 2016.

44. Wang R, Chen Z, Xu H, Schmidt K, Gu F, Ball A. Modelling and validation of a regenerative shock absorber system. Proceedings of 20th International Conference on Automation and Computing (ICAC'14). Cranfield, UK, 2014. p. 32-7.

45. Wang R, Crosbee D, Iwnicki S, Zhao Y, Bevan A. Power regeneration in the primary suspension of a railway vehicle. First International Conference on Rail Transportation, Chengdu, China, 2017.

46. Xu L, Guo XX, Liu J. Evaluation of Energy-Regenerative Suspension Structure Based on Fuzzy Comprehensive Judgment (FCJ). Advanced Materials Research, 2010, 139141:2636-42.

47. BS EN12299. Railway applications - ride comfort for passengers - measurement and evaluation, 2009;

48. Nadal J. Theory of Locomotive Stability, Part II: Yaw Motion. Annals of Mines, 1896.

49. RSSB. Railway Group Standard GM/RT2141: Resistance of railway vehicles to derailment and roll-over. 2009. 